\title{
A REFORMA TRIBUTÁRIA ECOLÓGICA ALEMÃ COMO PARADIGMA PARA O BRASIL
}

\author{
Julia Mattei \\ Doutora em Direito Ambiental Tributário e mestre em Direito Comparado (LL.M.) pela \\ Universidade de Colônia, Alemanha. Professora do mestrado profissional em Direito e Gestão \\ de Conflitos na Universidade de Fortaleza (Unifor). Pós-doutoranda do Programa de Pós- \\ Graduação em Direito da Universidade Federal do Ceará (UFC). \\ E-mail: juliamattei@unifor.br
}

\section{João Luis Nogueira Matias}

Doutor em Direito Comercial pela Universidade de São Paulo - USP (2009). Doutor em Direito Público pela Universidade Federal de Pernambuco (2003). Mestre em Direito e Desenvolvimento pela Universidade Federal do Ceará (1999). MBA em gestão de empresas pela FGV/MARPE (2005). Professor associado, nível III, da Universidade Federal do Ceará e do Centro Universitário 7 de Setembro - UNI7. E-mail: joaoluisnm@uol.com.br

\section{RESUMO}

O presente artigo traça um perfil da reforma tributária ecológica da Alemanha, com foco na tributação da energia, buscando analisar comparativamente os seus elementos com a finalidade de contribuir para uma ecologização do sistema tributário brasileiro. É traçado um paralelo entre os sistemas jurídicos dos dois países em relação à constitucionalidade dos impostos ecológicos sobre a energia (Ökosteuern), que na Alemanha foram introduzidos pela reforma tributária de 1999. No âmbito do direito brasileiro, é analisada a CIDE-Combustível, como ponto de partida para a ecologização do sistema tributário. A pesquisa é bibliográfica e documental. O método adotado é dedutivo-propositivo no contexto do direito comparado. O estudo mostrou que a constitucionalidade dos impostos ecológicos na Alemanha foi muito debatida, sendo a sua aprovação decorrente de motivos mais políticos do que jurídicos. No Brasil, a introdução integral deste modelo passa, de forma obrigatória, por uma alteração da Constituição. No entanto, são encontradas semelhanças importantes entre o modelo alemão e o modelo da CIDE-Combustível, podendo esta ser tomada como base para o "esverdeamento" do sistema tributário brasileiro.

Palavras-chave: Reforma tributária; tributação ambiental; impostos ecológicos; direito comparado; CIDE-Combustível. 


\title{
GERMANY'S ECOLOGICAL TAX REFORM AS PARADIGM TO BRAZIL
}

\begin{abstract}
This paper outlines a profile of Germany's ecological tax reform, focused on energy taxation, seeking to comparatively analyze its elements, contributing to the greening of the Brazilian tax system. To this purpose, a parallel is drawn between the legal systems of the two countries, analyzing the constitutionality of ecologically earmarked taxes on energy (Ökosteuern), which in Germany were introduced by the 1999 tax reform. Under Brazilian law, CIDE-Combustivel's (fuel tax) is scrutinized in its role as starting point for the greening of the tax system. The adopted method is deductive and suggestive in the context of comparative law. The study showed that the constitutional admissibility of the Ökosteuern in Germany was much debated and these were approved much more for political than legal reasons. In Brazil, the introduction of this taxation model depends inevitably on an amendment to the Constitution. However, important similarities are found between the German model and the CIDE-Combustivel's model and the last can be taken as kickoff for the "greening" of the Brazilian tax system.
\end{abstract}

Keywords: Tax reform; environmental taxation; ecotaxes; comparative law; CIDE-Combustivel. 


\section{INTRODUÇÃO}

A busca pela efetivação de normas relativas à proteção do meio ambiente segue intensa na conjuntura atual de agravamento da crise ecológica. No foco das preocupações está a busca por meios de redução da influência negativa do crescimento econômico sobre o meio ambiente, visando a melhoria da qualidade de vida da população mundial. Por outro lado, não há mais dúvidas de que os tributos, como forma de intervenção do Estado na economia, possuem um grande potencial de orientar o comportamento dos atores econômicos e consumidores de forma ecológica. Entretanto, em qual extensão esses instrumentos podem ser incluídos no sistema tributário de forma contínua é ainda um tema muito debatido. A intervenção diretiva do Estado, principalmente, é problemática em uma complexa ordem tributária que ainda luta por eficiência.

Dentre as diversas áreas da proteção ambiental em que a tributação poderia encontrar resultados eficientes, o setor de energia é campo frutífero para a introdução de tributos ambientais. Fontes de energia estão entre os recursos naturais mais valiosos para a economia e a geração de energia é um grande causador de emissões de $\mathrm{CO}_{2}$. A redução dessas emissões foi, por isso, o tema central do movimento ecológico europeu.

Os resultados positivos da política energética europeia podem ser tomados como exemplos para outros sistemas tributários, o que justifica a abordagem comparada.

Observa-se que o sistema tributário nacional ainda negligencia os recursos naturais, favorecendo produtos e comportamentos não ecológicos. E apesar do Brasil ter um dos maiores potenciais de energia renovável do mundo, a geração de energia advinda de fontes não renováveis ainda domina. Diante desse cenário, existe um grande interesse prático em uma análise comparativa dos aspectos constitucionais da proteção ambiental em países industrializados e em transição.

É inegável uma dimensão ecológica da dignidade da pessoa humana (FENSTERSEIFER, 2007), o que justifica não só a constitucionalização de direitos ecológicos, como também a interpretação ecologicamente orientada de todas as normas constitucionais, inclusive outros direitos fundamentais, normas de objetivos do Estado e da ordem econômica (MATTEI, 2016). Tanto o constituinte alemão quanto o brasileiro optaram por um modelo de proteção ambiental constitucional 
que permite essa compreensão.

O Brasil constitucionalizou a proteção ambiental de forma ampla no art. 225 da Constituição Federal de 1988 (CF) e, de forma mais específica, como princípio da ordem econômica no Art.170, IV, CF, exigindo, de forma direta, ponderações entre a proteção ambiental e os direitos econômicos (MATIAS; MATTEI, 2014).

Já a Alemanha optou pela inserção da proteção ambiental através de uma determinação normativa de objetivos do Estado no Art. 20a de sua Lei Fundamental (LF). Em relação à ordem econômica, o único dispositivo da Lei Fundamental que menciona a intervenção do Estado para regular a economia é o Art. 109, II, LF, que impõe ao Estado levar em conta, no cumprimento da disciplina orçamentária, as exigências do equilíbrio da economia em seu todo. Ao se interpretar a expressão "exigências do equilíbrio da economia em seu todo" de forma ecológica, em conformidade e devido à força de princípio do Art. 20a, LF, entende-se que este último dispositivo se apresenta como um verdadeiro imperativo, bem como uma limitação à intervenção do Estado na economia (MATTEI, 2016). Como se vê, apesar da constitucionalização da proteção ao meio ambiente, Brasil e Alemanha adotaram caminhos diversificados para a proteção constitucional (MATIAS; MATTEI, 2014), o que não afasta, mas sim potencializa a utilidade da comparação, com o objetivo de verificar se a reforma tributária alemã pode servir de parâmetro para o direito brasileiro.

De início, serão realizadas considerações sobre a reforma tributária alemã, abordando a ecologização da tributação sobre a energia, com destaque para a discussão sobre sua constitucionalidade. Em seguida, será abordada a regulação da CIDE-Combustível na ordem jurídica brasileira como exemplo de tributação ecológica. Na sequência, serão indicados caminhos para a alteração do sistema tributário brasileiro, com o objetivo de privilegiar a sua ecologização. Ao final serão apresentadas as conclusões.

A pesquisa é bibliográfica e documental. O método é dedutivopropositivo.

\section{A GUINADA ECOLÓGICA NA REFORMA TRIBUTÁRIA ALEMÃ}

Em meio ao discurso europeu do desenvolvimento jurídico da proteção ambiental, a discussão sobre a concretização de objetivos 
ambientais através do direito tributário ocorreu na Alemanha paralelamente à inserção da proteção ambiental na Lei Fundamental. Além da inserção de mecanismos tributários e da reestruturação de algumas espécies tributárias para melhor garantia da proteção ambiental, a Alemanha fez uso do modelo de tributação ambiental clássico dos impostos ambientais (Umweltsteuern), baseado na teoria de impostos de Pigou, entretanto com uma peculiaridade que torna o chamado Ökosteuer sui generis: a vinculação de sua receita ao sistema social, sendo, portanto, um imposto finalístico. Por este motivo, o termo usado no presente trabalho é o original Ökosteuer e não sua tradução literal como eco-imposto, para que não se confunda com outros tipos de tributação ecológica.

O conceito de tributo ambiental, seguindo o modelo de Pigou, ganhou popularidade quando introduzida a ideia de redução paralela de outros tributos, devendo os Ökosteuern serem vinculados à melhoria do sistema tributário geral (BAREIS; ELSER, 2000, p. 1180), visando solucionar o problema do fracasso do sistema social e do desemprego. Isso levou ao início de grandes debates no começo dos anos 90 sobre uma reforma do sistema tributário seguindo critérios ecológicos em nível constitucional.

O foco da reforma era colocar mais intensamente o sistema tributário a serviço da proteção ambiental. A reforma se desenvolveu, então, em torno do objetivo de transferir de forma parcial, neutra e a longo prazo, o ônus tributário do fator de produção "trabalho" para o fator de produção "recursos naturais" (JOBS, 1998, p. 1039), levando ao encarecimento da utilização de energia como resposta à problemática central do setor energético.

A reforma contou com quatro leis promulgadas entre 1999 e 2006: Lei para o Início da Reforma Tributária Ecológica (Gesetz zum Einstieg in die ökologische Steuerreform), Lei para a Continuação da Reforma Tributária Ecológica (Gesetz zur Fortführung der ökologischen Steuerreform), Lei para o Desenvolvimento da Reforma Tributária (Gesetz zur Fortentwicklung der ökologischen Steuerreform) e Lei do Imposto sobre Energia (Energiesteuergesetz - LIEn). Estas leis criaram o imposto sobre eletricidade (Stromsteuergesetz - LIEl) e alteraram gradualmente, segundo critérios ecológicos, o antigo imposto sobre petróleo (Mineralölsteuer), terminando por substituí-lo em 2006 pelo imposto sobre energia (Energiesteuer), conforme as diretivas da União Europeia sobre o tema.

Ambos são impostos indiretos sobre o consumo que seguem 
o modelo do tributo pigouviano, com a tributação do consumo para uso comercial e particular de energia (combustíveis como gasolina e diesel, óleo combustível, gás e eletricidade) e com o objetivo de internalizar os custos ambientais (poluição por não utilização de energias renováveis) no preço da energia, como se demonstrará a seguir.

\subsection{O modelo alemão dos impostos ecológicos sobre energia (Ökosteuern)}

Ökosteuer $n$ são, então, os impostos sobre energia (combustíveis) e sobre eletricidade. A competência para a instituição, cobrança e receita sobre ambos pertence à Federação (Art. 105, II c/c Art. 106, I, Nr. 2, LF).

$\mathrm{O}$ imposto sobre energia incide sobre o consumo de matéria-prima como o óleo mineral (petróleo), gás natural e carvão, quando eles sejam usados como combustível para a geração de energia (§ 1, II-III, LIEn). Para outras utilizações dessas matérias, a lei concede reduções (§ 2, II-III, LIEn) e isenções fiscais ( $\S \S 24-29,37,44$, LIEn). A reforma ecológica tributária trouxe ainda, por motivos político-ecológicos (SOYK, 2013), um catálogo extenso de desonerações fiscais, nos $\S \S 45$ ss. da LIEn, na forma de perdão, restituição e compensação do imposto. Paralelo à sua função extrafiscal, o imposto sobre a energia manteve a sua relevância fiscal para o orçamento. Sua receita vai, em regra, para o orçamento público, mas então é destinada, em parte, para o setor de estradas, segundo o Art. 1 da Lei de Financiamento da Estrutura Rodoviária (Straßenbaufinanzierungsgesetz) e o Art. 3 da Lei Financeira do Trânsito (Verkehrsfinanzgesetz). Além disso, as receitas correspondentes ao aumento das alíquotas desde a primeira reforma ecológica (Ökosteuer-Anteil) devem ser destinadas, através da Lei Orçamentária, à redução das contribuições sociais. Outrossim, as alíquotas do imposto são regulamente aumentadas para garantir a arrecadação.

O imposto sobre eletricidade foi baseado no modelo de tributação de $\mathrm{CO}_{2}$ proposto pela União Europeia e instituído como um imposto sobre o consumo. Fato gerador do imposto é a geração de energia elétrica $(\S 1$, I, LIEl). Contribuinte é o fornecedor ou o autoprodutor de eletricidade ( $\S$ 5 , II c/c $\S 2$, Nr. 1, LIEl), mas o ônus tributário pode ser, e normalmente é, transferido ao consumidor final ( $§ 5$, I, frase $1,1^{\text {a }}$ alternativa, LIEl). Por essa técnica, o imposto é incluído no preço da eletricidade. Visando a proteção ambiental e o fomento do uso de energias limpas, a eletricidade gerada de forma exclusivamente renovável (eco-eletricidade-Ökostrom) é 
isenta do imposto ( $§ 9, \mathrm{I}, \mathrm{Nr}$. 1, LIEl). Sua receita é destinada integralmente ao sistema social. Entretanto, o uso da receita obtida com o imposto sobre a eletricidade e com parte do imposto sobre energia para a redução das contribuições sociais não foi previsto, de forma expressa, nas leis tributárias (SOYK, 2013, p. 3), mas sim decorreu do processo legislativo (HAAS, 2005, p. 209) e é um dever do legislador orçamentário.

Para garantir a competitividade das empresas alemãs no comércio exterior, as indústrias manufatureiras e do setor agrícola, fortemente impactadas pelos Ökosteuern, recebem uma restituição do imposto pago através de uma "compensação adiantada" (Spitzenausgleich), ou seja, através do desconto do montante do imposto sobre eletricidade quando do pagamento do imposto de renda retido na fonte $(\S 10$, I, frase $2 \mathrm{c} / \mathrm{c} \S 9 \mathrm{~b}$, LIEl e $\S 55$, LIEn).

A inserção do novo modelo de tributação causou grande polêmica, como se verá a seguir.

\subsection{A constitucionalidade dos Ökosteuern}

A introdução dos Ökosteuern pela reforma tributária ecológica foi alvo de inúmeras críticas na literatura (ENGLISCH, 2013; LIST, 2000; SELMER, 2005) e foi submetida ao controle de constitucionalidade junto ao Tribunal Constitucional Federal alemão (TCF) como reclamação constitucional contra a violação de direitos fundamentais (BVERFG, 2004). Por isso, passa-se à análise de sua constitucionalidade, conforme a literatura e a jurisprudência do TCF.

O Ökosteuer, seguindo o modelo de tributação ambiental proposto por Pigou (que pode ser imposto, taxa ou contribuição), onera o causador de uma externalidade negativa (de dano ambiental) ao tributar atividades poluidoras, de forma que o imposto simule o preço do consumo ou da utilização de bens ambientais, na forma de produtos ou emissões, incluindo ou internalizando o custo da degradação ambiental nas decisões do agente econômico, levando a atividade poluidora a retroceder a um nível ótimo, tanto para o mercado quanto para o meio ambiente (STURM; VOGT, 2011). A estrutura do Ökosteuer corresponde à de um imposto de consumo clássico, podendo ser repassado pelo contribuinte ao consumidor. Com isso, os custos ambientais são devidamente distribuídos entre os responsáveis (produtores e consumidores) (AMARAL, 2008, p. 228; HESSELLE, 2004, p. 5; KLOEPFER, 2004, p. 189), cumprindo os 
princípios jurídico-ambientais do poluidor-pagador e do usuário-pagador. Tem, portanto, a finalidade extrafiscal de proteção ambiental.

A constitucionalidade de normas extrafiscais no direito tributário ou da intervenção do Estado através de impostos para influenciar comportamentos não é mais controversa na Alemanha (HEUN, 2008, p. 921; WEBER-GRELLET, 2001, p. 3657) e se fundamenta na admissibilidade geral da intervenção estatal na economia para proteger o mercado e garantir aos indivíduos uma existência digna e outros direitos fundamentais (DERANI, 2008). Além disso, a extrafiscalidade de impostos vem permitida expressamente no § 3, I, do Código Tributário alemão (Abgabenordnung), quando este prevê que a arrecadação de receitas (função fiscal) pode ser um objetivo secundário do imposto, embora deva estar sempre presente. Nesse sentido, impostos extrafiscais tiveram a sua constitucionalidade confirmada em diversas oportunidades pelo TCF (BVERFG, 1973, 1991, 2004). Normas extrafiscais para proteção ambiental se incluem nas "normas de objetivos sociais" (Sozialzwecknormen), que expressam ideais políticos e empregam a oneração ou desoneração tributária como incentivo a um determinado comportamento (GLASER, 2012, p. 168).

Para a análise da constitucionalidade do Ökosteuer importa saber, primeiramente, se ele pode ser caracterizado como imposto. O TCF confirma essa caracterização pelo fato de o Ökosteuer justificar um ônus geral, que é imposto a todos que realizam o fato gerador, bem como por sua cobrança ser independente de qualquer contraprestação individual e por ele gerar uma receita para o financiamento das atividades estatais (BVERFG, 2004).

Entretanto, o modelo pigouviano de tributação exige a vinculação de suas receitas. A extrafiscalidade deste tipo de tributo é, em sua forma original, a sua única função, conforme propõe Pigou, devendo sua receita ser vinculada para garantir a neutralidade do imposto e para que a sua função de correção da alocação de recursos seja cumprida (STURM; VOGT, 2011, p. 76). Assim, a receita do tributo pigouviano para proteção ambiental funciona como compensação ou indenização à sociedade por ser instrumento de criação de incentivos à redução de produtos ou emissões poluidoras. Serve, assim, como instrumento de financiamento e redistribuição de custos ambientais (KHAZZOUM; KUDLA; REUTER, 2011).

O legislador alemão optou, dentre as opções da tributação pigouviana na forma de impostos, taxas ou contribuições especiais, pelo 
imposto finalístico. Taxas, apesar de serem bons instrumentos para coibir comportamentos, são uma contrapartida para um serviço determinado, individualizável e público do Estado. Precisamente essa estrita vinculação das taxas constitui a sua limitação como instrumento da proteção ambiental (HEUN, 2008, p. 925), posto que, através delas, não é possível uma proteção global do meio ambiente. Em termos de contribuição especial (Sonderabgabe), instrumento equivalente ao instituto de mesmo nome no direito brasileiro, objeta-se justamente a finalidade de financiamento de atividade estatal do tributo ambiental pigouviano (SIEKMANN, 2014, p. 2165 s.), característica principal do imposto. No geral, contribuições especiais com essa finalidade são admitidas somente como raras exceções (BIRK; DESENS; TAPPE, 2014, p. 37). De acordo com o Art. 20a, LF, tarefas de proteção ambiental são tarefas gerais do Estado, e como tais devem ser financiadas, não por contribuições especiais, mas sim por meio de impostos. Além disso, a criação de contribuições especiais traz consigo o perigo de serem criados orçamentos paralelos ou mascarados, que não estariam mais à disposição do Estado (GOSCH, 1990, p. 210).

Segundo o direito tributário alemão, impostos ambientais são justificados como impostos finalísticos, uma vez que apenas dessa forma pode ser garantida a neutralidade da arrecadação e consequentemente a justiça fiscal (KUBE, 2014). Ecologicamente, o imposto ambiental finalístico é justificado quando ele é instrumento de arrecadação para o financiamento da proteção ambiental (WALDHOFF, 2007, p. 899 s.). Outra vantagem do imposto finalístico é que, no contexto da política orçamentária, o Estado é mais controlado em suas despesas através da vinculação das receitas e a moral tributária é elevada, uma vez que a instituição - sempre impopular - de novos tributos é vinculada a um objetivo de grande aceitação pela população (KISKER, 1990, p. 268 s.). Para a implementação da vinculação da receita são normalmente criados fundos ecológicos, que servem às tarefas estatais de proteção ambiental.

$\mathrm{Na}$ Alemanha, a proibição da vinculação das receitas de impostos deriva da expressão "obtenção de receitas" do $\S 3$, I, do Código Tributário e do Art. 110, I, LF, que determinam que a receita derivada da arrecadação de impostos será toda destinada ao orçamento público. O TCF admitiu a possibilidade de exceção a esta norma constitucional geral, bem como ao seu princípio concretizador da não-afetação de receitas (Gesamtdeckungsprinzip), previsto no $\S 7$ da Lei de Princípios Orçamentários (Haushaltsgrundsätzegesetz), quando a destinação de 
receitas para um objetivo determinado for prevista em lei ou no próprio plano orçamentário, não necessitando, por isso, de uma justificativa especial (KUBE, 2014). Segundo o TCF (2004, p. 294), os impostos finalísticos, especialmente os Ökosteuern, são constitucionais quando o montante vinculado não tenha tanto peso em comparação com o total da arrecadação do Estado através de impostos. Ou seja, o princípio da nãoafetação das receitas é um princípio do direito orçamentário, uma exigência político-financeira, mas não é um princípio constitucional (BVERFG, 1995, p. 348; GOSCH, 1990, p. 209). Somente uma vinculação em medida desproporcional, que realmente restringisse a liberdade de disposição orçamentária do legislador, não seria compatível com o princípio da nãoafetação (BVERFG, 1995, p. 348; SIEKMANN, 2014, p. 2146).

Aceita a admissibilidade de impostos finalísticos, resta saber se a vinculação das receitas a objetivos não-ecológicos é também constitucional no contexto do direito orçamentário.

Como visto, a Alemanha inovou ao trazer um imposto ambiental pigouviano vinculado não a fundos ecológicos, mas ao sistema social como um todo. Tendo em vista a crise do sistema social, devida principalmente ao envelhecimento da população e, assim, da continuidade de seu financiamento, buscou-se novas formas de manutenção do sistema social, sem que houvesse uma maior oneração das empresas. Desta feita, pela reforma tributária ecológica, desenvolveu-se o mecanismo de compensação entre o pagamento, pelas empresas, dos novos impostos sobre recursos naturais e o pagamento das contribuições sociais, permanecendo neutra para o empreendedor, pelo menos em teoria, a introdução de novos impostos.

Com a reforma tributária ecológica, visava-se, portanto, um dividendo duplo: de um lado a melhoria da qualidade ambiental através do estímulo à economia de energia e a consequente redução da poluição (LIST, 2000, p. 1216), e de outro, a redução do desemprego devido à desoneração do trabalho, além da garantia de continuidade (ao menos a médio prazo) do financiamento do sistema social. O almejado efeito ocupacional da reforma teve um papel fundamental na aceitação dos Ökosteuern, uma vez que a consecução apenas de objetivos ambientais ainda não seria motivo suficiente para um aumento considerável na carga tributária (STURM; VOGT, 2011, p. 72).

Apesar de politicamente excelente, a vinculação dos Ökosteuern não a fundos ecológicos, mas ao sistema social, esbarra em questões de 
justiça fiscal. Diferente do que ocorre com as contribuições especiais e sua vinculação a grupos específicos, na tributação ambiental alemã o grupo de contribuintes não coincide com o grupo beneficiado com o uso das receitas do imposto: setores de uso intensivo de energia (indústrias) são pesadamente tributados, enquanto setores econômicos de uso intenso de trabalho (serviços) são os mais beneficiados pela queda das contribuições sociais. De forma individual, somente aqueles contribuintes dos Ökosteuern que são obrigados a pagar contribuições sociais beneficiam-se da diminuição destas, e não empresários individuais, servidores públicos, estudantes e aposentados, todos contribuintes indiretos dos impostos (LIST, 2000, p. 1218). O TCF, ao lidar com a questão dessa necessidade do nexo entre ônus tributário e uso das receitas, no caso dos impostos finalísticos, apenas declarou que os grupos atingidos não precisam ser equivalentes (SELMER, 2005, p. 414 s.; WALDHOFF, 2002, p. 304).

A caracterização dos Ökosteuern como impostos depende ainda da existência da função fiscal dos impostos. Quando esta é excluída na prática, resta ferido o princípio da proibição de impostos "estrangulantes" (Erdrosselungssteuer) ou da proibição de confisco. Como a ideia do imposto extrafiscal é coibir um determinado comportamento, fato gerador do imposto, quanto mais sucesso ele obtiver, mais sua arrecadação tenderá a zero. No caso de impostos ambientais, isso não costuma ocorrer, devido a uma técnica utilizada para evitar a exclusão da função fiscal do imposto: o aumento periódico de alíquotas, garantindo a arrecadação (JACHMANN, 2004, p. 709). Assim sendo, a arrecadação zero, no caso de impostos ambientais, não é de se esperar (BALMES, 1997, p. 153; HAAS, 2005, p. 208), de forma que o Ökosteuer é constitucional sob esse aspecto (BIRK; DESENS; TAPPE, 2014, p. 63; GOSCH, 1990, p. 214).

Outro aspecto a ser considerado é o fato de o Ökosteuer ser um imposto que pretende coibir uma atividade econômica, podendo acabar por impedi-la, o que também caracterizaria um confisco. O imposto pigouviano, entretanto, deixa um espaço de liberdade de escolha ao sujeito econômico (ele pode não realizar a conduta e não pagar imposto ou continuar a realizála, pagando-o). Somente se essa possibilidade de escolha fosse excluída estaria presente uma inconstitucionalidade. Isto aconteceria quando o bem que se quer proteger ao tributar é tão essencial à vida que a tributação não pode ser evitada. Esse é o caso do consumo de água e ar, por exemplo, nos quais a elasticidade da demanda é baixa (STURM; VOGT, 2011, p. 77). No entanto, através de outras técnicas tributárias como redução de 
alíquotas e isenções fiscais, o valor do imposto pode ser ajustado de forma a ser evitada a exclusão da escolha, permanecendo assim o imposto como constitucional.

Em termos de competência para a instituição do Ökosteuer, a federação (Bund) tem a competência concorrente para instituir impostos sobre o consumo, contanto que não coincidam com impostos arrecadados pelos estados federados (Art. 105, II c/c Art. 106, I, Nr. 2, LF). Algumas vozes na literatura questionaram a constitucionalidade do Ökosteuer por ser ele um imposto sobre o uso de recursos naturais na cadeia produtiva, $\mathrm{o}$ que o tornaria imposto empresarial (e não de consumo) (JOBS, 1998, p. 1042). Entretanto, assim como nos impostos sobre produção e distribuição de mercadorias, pela técnica do repasse da tributação ao consumidor, o consumo do bem pela indústria/empresa não será tributado (BVERFG, 2004).

Apesar da função primordial extrafiscal do Ökosteuer, ele deve obedecer aos princípios constitucionais tributários. A extrafiscalidade dos impostos ou de normas tributárias sempre foi e será alvo de inúmeras críticas, posto que sua inserção no sistema tributário leva ao conflito entre a rigidez do princípio da legalidade no direito tributário e a necessidade da flexibilidade em um instrumento de intervenção estatal (SCHOUERI, 2005, p. 240), levando à desestabilização da desejável segurança jurídica do sistema. A legalidade entende-se assegurada quando o imposto seguir os seus subprincípios, como anterioridade e não retroatividade da lei tributária e precisão de definições (objetivos, fato gerador, contribuintes, alíquotas), entre outros. Já a questão da igualdade tributária nos impostos extrafiscais é mais complexa pela atenção ao princípio da capacidade tributária. Segundo a literatura e jurisprudência alemãs, é aceitável uma quebra desse princípio quando há um motivo válido para tanto (BALMES, 1997, p. 162; HEY, 2015, p. 74; SCHOUERI, 2005, p. 246). No caso dos impostos ambientais, fala-se em "relevância ecológica do ônus" (ökologische Belastungswürdigkeit) (BALMES, 1997, p. 163), determinada pela análise dos critérios de proporcionalidade ou de proibição do excesso (Übermaßverbot): adequação, exigibilidade e ponderação.

A adequação do imposto é primeiramente constatada quando ele objetiva atender a um determinado interesse público ou ao bem comum. Serve ao interesse público tudo o que consolida, mantém ou melhora as condições de subsistência da comunidade e seus integrantes (TIPKE, 2000, p. 341), não restando dúvidas de que a proteção ambiental é essencial para 
a subsistência digna da pessoa humana (MATTEI, 2016). Avalia-se aqui também se o imposto é um meio adequado para se atingir esse determinado interesse público, ou seja, se uma mudança de comportamento do contribuinte em um sentido ambientalmente correto pode ser alcançada pela cobrança do imposto ambiental. O TCF alemão dá ao legislador tributário essa prerrogativa em casos de extrafiscalidade (MÖSLEIN, 2012, p. 247), o que não exclui uma análise mais detalhada das consequências econômicas da inserção do imposto no caso concreto.

A exigibilidade do imposto ambiental é verificada quando o objetivo da tributação não pode ser alcançado por algum outro meio mais brando e de mesma eficácia (BALMES, 1997, p. 157). Diferente de outros instrumentos econômicos que podem ser utilizados para a proteção ambiental e que implicam uma mudança no comportamento do poluidor, o modelo de tributação ambiental mostra-se, ao lado do mercado de certificação de emissões, mais brando do que mecanismos de comando e controle, por possibilitar ao contribuinte uma escolha, sendo portanto um instrumento econômico flexível (BERNARDI, 2008, p. 65; KIRCHHOF, 1993, p. 592; SOUZA FILHO, 2012, p. 336). Em relação ao mercado de emissões, possui a vantagem de não depender das flutuações e variações características do mesmo.

Para ser constitucional, o imposto ambiental deve ainda ser razoável, ou seja, deve ser resultado de uma ponderação entre o interesse público na proteção ambiental e a intervenção na esfera privada individual dos contribuintes. No contexto da atual crise ambiental de esgotamento dos recursos naturais, a intensidade da intervenção é vista em geral como apropriada (BALMES, 1997, p. 159), não excluindo também uma análise da razoabilidade da medida no caso concreto.

Após essa análise preliminar da relevância ecológica da tributação, deve o legislador tributário atentar ainda para o princípio da igualdade em sentido estrito. A proteção ambiental, como matéria, passa a ser, então, o critério para a justiça da tributação (HEY, 2015, p. 101), e esta deve ser tanto maior quanto mais poluidor for o comportamento onerado. Como critério de comparação para determinação de desigualdades é utilizado o princípio da equivalência e o subprincípio do benefício (HEY, 2015, p. 75), ambos refletindo o ideal de justiça fiscal baseado na capacidade contributiva. Ocorre que, como visto, são concedidas subvenções fiscais a determinados contribuintes, como empresas com consumo intenso de energia, por razões não-ecológicas, principalmente contra a perda de competitividade dessas 
empresas no mercado externo. O TCF (2004, p. 297 s.) justificou tal quebra no princípio da igualdade em relação à justiça ambiental alegando que as subvenções são ligadas a características subjetivas do consumidor e não ao consumo em si, não devendo ser avaliadas pelos critérios materiais ambientais, e sim econômicos. Nesse sentido, aduz que o legislador pode perseguir diversos objetivos com um mesmo tributo e distinguir diversos grupos de contribuintes, impondo-lhes regras diferentes. A diferenciação é, nesse caso, válida, uma vez que a norma subvencionadora é dirigida à finalidade de garantir a neutralidade da tributação, preservando a competitividade empresarial.

A decisão do TCF pela constitucionalidade das leis da reforma tributária ecológica não saiu ilesa de críticas: por um lado, alegou-se que a corte foi superficial ao declarar que os grupos de contribuintes e beneficiários dos Ökosteuern não precisam ser correspondentes entre si, sem abordar a questão da justiça fiscal envolvida. Por outro, entende-se que as normas de exceção para empresas extremamente poluidoras não são justificáveis ecologicamente, contrariando a finalidade dos impostos (HESSELLE, 2004, p. 64; SELMER, 2005, p. 424), e que essa quebra da finalidade ecológica da reforma não foi aprofundada pelo TCF de forma satisfatória (HAAS, 2005, p. 212). Também foi deixada de lado a análise da conformidade dos Ökosteuern com os princípios do direito orçamentário (HAAS, 2005, p. 212). Além disso, os critérios de adequação, necessidade e proporcionalidade da tributação em tela não foram avaliados ponto a ponto (HAAS, 2005, p. 213).

Apesar das polêmicas, não há dúvida que a reforma abriu novas perspectivas para a ecologização da tributação.

\section{A CIDE-COMBUSTÍVEIS COMO TRIBUTO AMBIENTAL BRASILEIRO}

O tema da proteção ambiental foi introduzido na discussão sobre a reforma tributária também no Brasil. Apesar de serem observados alguns avanços nesse tema, muitas tentativas de mudanças ecológicas fracassaram. O sistema tributário brasileiro ainda é, especialmente em nível constitucional, pouco ecológico (BLANCHET; OLIVEIRA, 2014, p. 163; COSTA, 2011, p. 340). Apesar de existirem regras tributárias pontuais relacionadas à proteção ambiental, falta ainda ao direito tributário brasileiro um sistema claro de regras que possam levar a uma efetiva 
proteção ambiental. Não obstante o mandamento da proteção ambiental, tanto como um direito fundamental, quanto como princípio da ordem econômica, seu grau de abstração dificulta ainda a sua concretização no campo do direito tributário.

Dentre os diversos mecanismos tributários, a CIDE-Combustíveis é ainda o único instrumento que realmente apresenta de forma direta efeitos ecologicamente relevantes. Neste caso, a intervenção estatal se justifica pela necessidade de subsidiar os preços ou o transporte de álcool combustível, gás natural e seus derivados, e derivados de petróleo, uma vez que estes são fundamentais ao desenvolvimento da nação (CUNHA; BEZERRA, 2011, p. 316). Apesar da motivação para sua instituição ter sido de natureza econômico-fiscal, esta contribuição especial pode ser vista como um passo importante no uso da tributação para a diminuição das emissões de $\mathrm{CO}_{2}$, aproximando-se, nesse sentido, do Ökosteuer alemão.

A CIDE-Combustíveis é uma contribuição de intervenção no domínio econômico, de competência da União, nos moldes do Art. 149, caput e $\S 2, \mathrm{CF}$, constitucionalizada especificamente no Art. 177, § 4, CF. Ela tributa atividades de importação ou comercialização de petróleo e seus derivados, gás natural e seus derivados, e álcool combustível. Assim, segue a estrutura de um tributo indireto sobre o consumo, tendo como contribuintes diretos os produtores, importadores e comerciantes, e, indiretos, os consumidores finais, por meio da técnica de transferência do imposto no preço do produto ou serviço. Sua receita é vinculada, através das leis orçamentárias anuais, ao pagamento de subsídios a preços ou transporte de álcool combustível, gás natural e seus derivados, e derivados de petróleo; ao financiamento de projetos ambientais relacionados com a indústria do petróleo e do gás; e ao financiamento de programas de infraestrutura de transportes (Art. 177, § 4, II, CF e Art. 1, § 1, Lei 10.336/01). O STF (AI 737858 ED-AgR/SP, 2012) deixou claro que não é necessária a vinculação direta entre os benefícios decorrentes de uma CIDE e o contribuinte. Entretanto, sua receita deve financiar atividades relacionadas ao setor ou ao grupo econômico alcançado pela intervenção, devendo, assim, existir ao menos um mesmo contexto entre o uso das receitas e a área econômica tributada, para garantir a neutralidade do tributo, o que nem sempre ocorre (CUNHA; BEZERRA, 2011).

A contribuição em análise traz questionamentos quanto à sua constitucionalidade. Uma vez que a sua destinação faz parte de seu fato gerador (CHARNESKI, 2006, p. 15 s.; SANTI et al., 2008, p. 61), as leis 
orçamentárias que estabelecem de forma detalhada a destinação de suas receitas também devem ser submetidas ao controle de constitucionalidade do tributo (DOMINGUES; MOREIRA, 2009, p. 226). A CIDE só será constitucional quando a sua lei instituidora determinar de forma precisa o seu objetivo e quando as receitas provenientes de sua arrecadação sejam destinadas pelas leis orçamentárias a esses objetivos (GOMES, 2008). Sob esse aspecto do cumprimento de sua destinação constitucional, grande parte da literatura especializada, como Domingues e Moreira (2009), Tôrres (2012) e Gomes (GOMES, 2008), entende que a CIDE-Combustíveis é deficiente, devendo sua constitucionalidade ser anualmente avaliada conforme a lei orçamentária.

Segundo a definição da OCDE (2005), a CIDE-Combustíveis é considerada um tributo ambiental ("environmental tax"), pois taxa uma unidade física que tem um impacto negativo comprovado no meio ambiente (combustível poluente), o que atende ao princípio do poluidorpagador. Entretanto, é relevante para o conceito amplo de tributo ambiental que o mesmo tenha o potencial de gerar efeitos ecologicamente positivos, não só pela mudança do comportamento dos contribuintes no consumo de combustíveis, mas também pela utilização de sua receita (MATTEI, 2016). Assim, o sucesso da função extrafiscal do tributo ambiental pode ser confirmado pela análise estatística do comportamento dos agentes econômicos e pela avaliação do emprego adequado de suas receitas.

Analisando-se o impacto da CIDE-Combustíveis sobre o comportamento dos agentes econômicos, tem-se que, em se tratando de combustíveis, um aumento do ônus tributário sobre o seu consumo não implica necessariamente em mais eficiência (GUSMÃO, 2006, p. 129), em especial quando não há uma alternativa mais barata ou equivalente ao combustível poluente. Em uma análise comparativa da carga tributária média incidente sobre gasolina (muito poluente) e etanol (pouco poluente), Tôrres (2012) constata, por exemplo, que em 2012 esta era de 36,79\% para a gasolina, contra $31,92 \%$ para o etanol. Além disso, a alíquota da CIDE-Combustíveis foi zerada de 2012 a 2015 (Decreto Nr. 7.764/2012 e Decreto Nr. 8.395/2015), reduzindo o preço da gasolina. A diferença entre combustíveis mais e menos poluentes é ainda pequena, e a tributação do etanol é ainda muito elevada. Com isso, o consumo de etanol não é favorecido em contraposição ao consumo de gasolina, como o princípio da proteção ambiental, na verdade, exige (TÔRRES, 2012). Observa-se que fatores político-econômicos ainda imperam nas decisões estatais, 
provocando uma desoneração da utilização de combustíveis fósseis (REIS; FERREIRA, 2017, p. 172).

A vinculação da receita da CIDE-Combustíveis, em parte, a projetos ambientais, confirma seu caráter ecológico (REIS; FERREIRA, 2017, p. 167; SOUZA FILHO, 2012, p. 337). Assim, são financiados projetos ambientais relacionados à indústria do petróleo e gás natural e à melhoria da infraestrutura de transportes, o que pode afetar positivamente o meio ambiente. Entretanto, outras possíveis destinações de sua arrecadação podem gerar efeitos prejudiciais ao meio ambiente, uma vez que sua receita é vinculada também ao subsídio de combustíveis poluentes (Art. 177, § 4, II, $a$, CF). Com a Lei 10.336/2001, era esperada a criação de um fundo para proteção ambiental no campo de combustíveis para o produto da arrecadação da CIDE-Combustíveis, o que, junto ao Projeto de Lei 623/2003 para a criação do Fundo para Reparação de Danos Ambientais Causados por Poluição por Hidrocarbonetos, contemplado com recursos da CIDE-combustível, fracassou (DOMINGUES; MOREIRA, 2009, p. 228; TÔRRES, 2012).

Do exposto, depreende-se que a CIDE-Combustível, mesmo tendo como função principal a fiscal, pode ser caracterizada como um tributo ambiental. Ela tem, em teoria, um efeito positivo no meio ambiente e pode, portanto, ser caracterizada como uma intervenção estatal ecológica na economia. Além do efeito ecológico quando de sua cobrança, o produto da arrecadação da contribuição é utilizado, embora apenas em parte, para o financiamento de programas ambientais. Sua maior parte é, entretanto, utilizada para garantir a neutralidade do tributo, beneficiando os contribuintes através, por exemplo, da construção, manutenção e melhoria de estradas e rodovias, e subsidiando o preço dos combustíveis poluentes, o que pode ir de encontro à proteção ambiental.

Assim, embora sua estrutura e finalidade a aproxime dos Ökosteuern, principalmente do imposto sobre energia, a CIDECombustíveis é apenas em parte destinada à proteção ambiental e ainda assim, na prática, é questionável a sua aplicação aos fins previstos.

\section{PERSPECTIVAS DE UMA REFORMA TRIBUTÁRIA ECOLÓGICA NO BRASIL}

A necessidade de uma reforma do sistema tributário brasileiro é inegável. A regulamentação do sistema data de 1966 e a estrutura 
dos principais impostos e repartição de receitas continuam desde então praticamente imutáveis, tendo a Constituição de 1988 integrado esse sistema em sua ordem tributária e orçamentária.

Em meio a algumas tentativas, umas com propostas mais consistentes em termos ecológicos, como a arquivada PEC 353/09, e outras com propostas pontuais relativas à proteção ecológica, como a PEC 41/03, transformada na Emenda Constitucional 42, a ideia de uma grande reforma na essência do sistema tomou proporções mais concretas desde 2007 em diversas propostas de emendas constitucionais, que entraram como apensas à PEC 31/07 na Câmara dos Deputados. Esta PEC e apensos ainda se encontram, desde 2008, pendentes de votação. Segundo Pereira e Ferreira (2010), apesar do principal objetivo da PEC 31/07 ser a redução da cumulatividade do sistema através da desoneração do trabalho e da inserção de um imposto sobre o valor agregado federal, ela define a proteção ambiental como um de seus objetivos. De acordo com a justificação da PEC 31/07, a proteção ambiental seria promovida especialmente através da transferência de parte da receita do ICMS às cidades (ICMS-Eco) e através da cobrança do IPI segundo critérios ambientais, mas as alterações ecológicas se resumiriam a essas medidas.

Mesmo com a possível aprovação da PEC 31/07, o sistema tributário ainda deixará a desejar em termos ecológicos. A inserção de uma CIDE-Ecológica ou de um imposto ambiental é ainda uma ideia longe de poder ser concretizada, mas uma análise de sua viabilidade contribui para a discussão da reforma tributária.

Um tributo ambiental na forma de uma CIDE-Ecológica de competência da União estaria constitucionalmente amparado no Art. 149, $\mathrm{CF}$, que não determina um fato gerador específico para as CIDE e delega sua formatação ao legislador infraconstitucional (SILVA; ELALI, 2012, p. 61). No entanto, a intervenção estatal através de contribuições sobre o domínio econômico só se justifica quando objetiva a proteção da ordem econômica e observa seus princípios, especialmente o desenvolvimento sustentável de cada área econômica (STJ, REsp 1120553/RJ, 2010). Por área econômica, entende-se aqui cada parte da ordem econômica na qual atores privados atuam e para a qual é exigida uma intervenção estatal para fiscalização, controle, incentivo e planejamento. Além disso, a CIDE deve ser temporária, devido ao seu caráter excepcional no contexto do sistema tributário (TÔRRES, 2005, p. 140): segundo o Art. 177, § 4, CF, ela é exceção aos princípios constitucionais tributários da legalidade e da 
anterioridade do exercício financeiro (CUNHA; BEZERRA, 2011, p. 314). Para que sua receita seja neutra, ela não pode passar pelo orçamento público, mas sim deve ser empregada na própria área que sofreu a intervenção, à qual pertence o contribuinte (COSTA, 2012, p. 96; CUNHA; BEZERRA, 2011), de forma que sua função extrafiscal seja diretamente realizada e completamente implementada.

A CIDE-Ecológica seria então constitucional, se os pressupostos do Art. 149, § 2, CF forem observados. Assim, ela também precisaria representar uma intervenção em uma determinada área econômica e utilizada como instrumento de atuação nesta, além de buscar a proteção da ordem econômica e de seus princípios. Costa (2011, p. 345) cita como exemplo uma CIDE que onere a indústria madeireira para o financiamento de programas de reflorestamento.

No entanto, a CIDE-Ecológica restaria limitada à área econômica alvo da intervenção, e o nexo entre utilização das receitas e os contribuintes deve existir. Apesar dos contribuintes não arcarem com o ônus da tributação, que é repassado aos consumidores finais, a CIDE influi de forma considerável em suas chances de concorrência no mercado e deve, portanto, retornar como compensação quando do emprego das receitas tributárias, tornando-se neutra. Perante a ideia de serem inseridas novas contribuições especiais no modelo da CIDE-Combustível, deve-se considerar ainda que o legislador constitucional brasileiro é confrontado com o problema recorrente de que tributos extrafiscais são frequentemente desviados de sua finalidade original (HARADA, 2013, p. 30 s.). Eles são, por exemplo, criados como exceções aos rígidos princípios da tributação e são utilizados para um aumento da carga tributária. Por isso, é recomendado cuidado com a inserção de tais tributos, especialmente das CIDEs, as quais, como contribuição, têm pressupostos constitucionais menos rígidos que os impostos.

Por outro lado, a ideia de inserir um imposto ecológico de acordo com o modelo proposto por Pigou não é nova na literatura nacional, mas pode esbarrar em princípios constitucionais. Normas extrafiscais no direito tributário brasileiro podem ser encontradas na própria Constituição brasileira e sua admissibilidade vem sempre sendo confirmada pela jurisprudência dos tribunais superiores. A extrafiscalidade de impostos, fundamentada no conceito de imposto do Art. 16 do CTN, que não exclui a persecução de outras finalidades pelo imposto, consolidou-se tanto na teoria como na prática do direito tributário. Sua constitucionalidade, 
assim como no direito alemão, fundamenta-se na admissibilidade geral da intervenção estatal na economia para proteger o mercado e garantir aos indivíduos uma existência digna e outros direitos fundamentais (DERANI, 2008). Uma infração ao Art. 3 do CTN, quando este determina que o tributo não pode ser sanção por ato ilícito, não vem ao caso, posto que o consumo de combustíveis poluente não é proibido, mas deve ser desencorajado, ao menos em um primeiro momento (SCHOUERI, 2005, p. 252).

A problemática dos impostos ambientais e a proibição do confisco também é tema relevante para o direito pátrio. Isso porque, segundo o Art. 150, IV, CF, o tributo não pode ser utilizado com efeito de confisco. Como já analisado, mesmo sendo o consumo de bens ambientais essencial para a vida e para as atividades econômicas, a possibilidade de escolha do contribuinte entre pagar o imposto ou não, bem como a aplicação de técnicas tributárias como a concessão de subvenções, podem assegurar a constitucionalidade do tributo nesse aspecto. Em termos de competência tributária, a União tem a competência para instituir novos impostos, desde que sejam não cumulativos e não tenham fato gerador ou base de cálculo próprios dos discriminados na Constituição (Art. 154, I, CF). Um imposto ambiental como imposto indireto sobre o consumo de combustíveis não encontraria problemas constitucionais, contanto que seja preservada a sua não-cumulatividade com outros tributos. Em relação à sua conformidade com outros princípios do direito tributário, um imposto ambiental pode ser constitucionalmente admissível, conforme análise já feita para os Ökosteuern.

Um imposto ecológico ou ambiental com a finalidade principal de coibir comportamentos poluentes sem vinculação de receitas, certamente encontraria resistência da população. $\mathrm{O}$ aumento da já altíssima carga tributária, a não vinculação da arrecadação a programas ambientais e, especialmente, a falta de transparência do orçamento no Brasil dificultam a justificativa de uma decisão política para a criação de um imposto ambiental. Também deveria ser analisado economicamente de que forma um imposto neste modelo modificaria a realidade econômica do país, uma vez que o preço da energia seria elevado consideravelmente.

Questão fundamental para a análise de constitucionalidade de um hipotético imposto ambiental no Brasil é, então, a vinculação obrigatória das receitas do modelo pigouviano, que visa garantir a sua neutralidade. No Brasil, a proibição da vinculação da receita de impostos é deduzida do Art. 16 do CTN, que os define como independentes de qualquer atividade estatal 
específica. Além disso, a Constituição veda ao legislador orçamentário a vinculação de receita de impostos a órgão, fundo ou despesa, com exceção da vinculação em prol de saúde, educação e administração tributária (art. 167, IV, CF). Com isso, conclui-se que um imposto ambiental com vinculação de receitas, quer para a proteção ambiental, quer para o sistema social, é inconstitucional. Para a sua inserção no sistema tributário, seria necessária uma emenda constitucional, que incluísse no Art. 167, IV, CF o objetivo "proteção ambiental" ou - visando imposto equivalente ao Ökosteuer - o objetivo "seguridade social".

A ideia de um imposto no modelo do Ökosteuer alemão, com vinculação da receita à desoneração do fator trabalho, representaria uma alternativa econômico-política à criação de um imposto ambiental pigouviano. Como no Brasil também existe o grande problema da alta carga tributária sobre empresas devido à grande quantidade de tributos sociais, um Ökosteuer poderia ajudar na desoneração das empresas. Sob a ótica empresarial, o modelo alemão tem a vantagem de que a arrecadação do imposto é usada diretamente em seu benefício por meio do sistema de compensação antecipada, mesmo que seja compensada apenas parte do valor pago com o sistema social. Nesse caso, o fato de as receitas arrecadadas serem utilizadas diretamente em uma área relevante para a população (sistema social) aumenta a aceitação do imposto pela população, o que elevaria a moral fiscal e provavelmente levaria a um retrocesso da evasão fiscal.

No Brasil, é ainda problemática a concentração do sistema na tributação do consumo. Gassen et al. (2013, p. 215-230) constatam que o Estado, em países emergentes e em desenvolvimento, concentra sua arrecadação fiscal na tributação do consumo: no Brasil, a tributação ao consumo representa $68,20 \%$ da arrecadação total do Estado, enquanto esta porcentagem nos países da OCDE é em média de 30,4\%. Isso leva a uma matriz tributária regressiva e, consequentemente, também a um fortalecimento da desigualdade social. No Brasil, onde, devido a essa regressividade do sistema, as camadas sociais mais baixas, com pouca ou nenhuma renda, são proporcionalmente mais tributadas (GASSEN; D'ARAÚJO; PAULINO, 2013, p. 223). Um imposto adicional indireto somente iria agravar a desigualdade.

O fracasso das PECs com propostas ecológicas demonstra como é complicado realizar uma grande reforma que passe pela inserção de tributos extrafiscais para a proteção ambiental conforme princípios ecológicos. Para 
isso, a implementação da tributação ambiental deveria ser gradual e levar em consideração a eficiência ambiental do instrumento, sua eficácia para atingir os objetivos específicos, equidade, aceitação política, viabilidade administrativa e sua flexibilidade em se adaptar a mudanças (ALVES; PORTUGAL JÚNIOR; REYDON, 2017, p. 77). Concorda-se com Alves et al. (2017) quando concluem que a aplicação de tributos ambientais, como uma CIDE-Ecológica ou um imposto ambiental, bem como de qualquer política ambiental de aplicação de instrumentos econômicos, deve ser vinculada com outras políticas de governo para que haja um sincronismo entre os objetivos conflitantes do crescimento econômico e da preservação do meio ambiente. Por isso, mostra-se mais fácil e oportuno realizar pequenas adaptações ao sistema tributário vigente, ao invés de serem criados novos impostos ambientais (FIORILLO; FERREIRA, 2010; SILVA; ELALI, 2012; TÔRRES, 2012).

Apesar de suas deficiências, a CIDE-Combustíveis é considerada um tributo ambiental e uma ecotax - segundo a definição da OCDE - que pode ser vislumbrada como um início para uma reforma tributária ecológica mais abrangente. O próximo passo mais adequado a uma ecologização do sistema tributário seria uma abdicação de receitas por parte do Estado, através de uma maior concessão de subvenções fiscais para atividades nãopoluentes (CAVALCANTE, 2011, p. 366). No contexto da mudança de paradigma para um Estado de Direito Ecológico, essa adequação ecológica gradual do sistema tributário nacional deve levar a uma sistematização segundo critérios ecológicos - do sistema tributário com foco em tributos ambientais (CAVALCANTE, 2011, p. 363).

\section{CONCLUSÃO}

No contexto da reforma tributária ecológica da Alemanha, os Ökosteuern, impostos finalísticos baseados no modelo de tributação proposto por Pigou, foram inseridos com sucesso no sistema tributário. Devido à vinculação de sua receita à desoneração do "fator trabalho", ou seja, a gastos com o sistema social, os Ökosteuern receberam boa aceitação por parte dos cidadãos e empresários. Apesar das críticas que se dirigiram principalmente à falta de competência para sua cobrança, à falta de neutralidade das receitas, à perda de competitividade no comércio internacional, à criação duvidosa de nova fonte de renda e a outros problemas de desigualdade tributária, sua constitucionalidade foi declarada 
pelo Tribunal Constitucional Federal, o que inaugurou um novo capítulo na ecologização da ordem jurídica alemã. Atualmente o "esverdeamento" do sistema tributário concentra-se na melhoria das técnicas dos Ökosteuern para minimizar suas pontuais injustiças.

Pode ser ainda observado que o imposto pigouviano se mostra como instrumento eficiente e ecologicamente justo para a intervenção estatal na economia, sendo ainda preferível a outras formas de intervenção mais rígidas. Este imposto ambiental pode ser projetado de forma a ser admissível constitucionalmente, tanto por critérios da Lei Fundamental alemã como da Constituição Federal do Brasil. No entanto, no Brasil, a proibição expressa da vinculação da receita advinda de impostos é um obstáculo para a sua implantação, transponível apenas através de uma reforma constitucional.

Tendo em vista a inconstitucionalidade de um imposto pigouviano no Brasil e as limitações de uma CIDE-Ecológica, parecem mais adequadas modificações na já existente CIDE-Combustíveis, que pode ser considerada um tributo ambiental e tem o potencial de desencadear uma reforma tributária ecológica mais abrangente.

\section{REFERÊNCIAS}

ALVES, Alessandro Ferreira; PORTUGAL JÚNIOR, Pedro dos Santos; REYDON, Bastiaan Philip. Política econômica ambientalmente sustentável: por uma adaptação de fundamentos macroeconômicos à sustentabilidade ambiental. Revista Ciências Humanas. Taubaté, v. 10, n. extra, p. 72-89, 2017.

AMARAL, Paulo Henrique do. Tributação ambiental: contributo à política de desenvolvimento sustentável no Brasil. Revista de Direito Ambiental. São Paulo, v. 13, n. 50, p. 212-234, 2008.

BALMES, Frank Rainer. Verfassungsmäßigkeit und rechtliche Systematisierung von Umweltsteuern. Lohmar: Eul, 1997.

BAREIS, Peter; ELSER, Thomas. Anforderungen an Lenkungssteuern und Beurteilung der "ökologischen Steuerreform" aus ökonomischer Sicht. Deutsches Verwaltungsblatt. Köln, n. 16, p. 1176-1185, 2000.

BERNARDI, Renato. Tributação Ecológica: O uso ambiental da 
extrafiscalidade e da seletividade tributárias. Revista Magister de Direito Ambiental e Urbanístico. Porto Alegre, v. 3, n. 15, p. 55-76, 2008.

BIRK, Dieter; DESENS, Marc; TAPPE, Henning. Steuerrecht. 17. ed. Heidelberg: C. F. Müller, 2014.

BLANCHET, Luiz Alberto; OLIVEIRA, Edson Luciani de. Tributação da energia no Brasil: necessidade de uma preocupação constitucional extrafiscal e ambiental. Sequência. Florianópolis, v. 35, n. 68, p. 159-187, 2014.

BUNDESVERFASSUNGSGERICHT (BVERFG). Stabilitätszuschlag, BVerfGE 36, p. 66 ss., 1973.

BUNDESVERFASSUNGSGERICHT

(BVERFG).

Kapitalertragssteuer, BVerfGE 84, p. 239 ss., 1991.

BUNDESVERFASSUNGSGERICHT (BVERFG). Wasserpfennig, BVerfGE 93, p. 319 ss., 1995.

BUNDESVERFASSUNGSGERICHT BVerfGE 110, p. 274 ss., 2004.

(BVERFG). Ökosteuern,

CAVALCANTE, Denise Lucena. Reflexões sobre a tributação ambiental. Interesse Público. Belo Horizonte, v. 13, n. 68, p. 355-368, 2011.

CHARNESKI, Heron. Desvio orçamentário de finalidade das contribuições à luz do federalismo fiscal brasileiro: o caso Cide-combusíveis. Revista dialética de direito tributário. São Paulo, n. 128, p. 13-25, 2006.

COSTA, Regina Helena. Apontamentos sobre a Tributação Ambiental no Brasil. Lusíada Direito e Ambiente. Lisboa, n. 2-3, p. 329-348, 2011.

COSTA, Milena Rosado da. As espécies tributárias como instrumento destinado a tutelar bens ambientais. juris rationis. Natal, v. 5, n. 2, p. 8998, 2012.

CUNHA, Danillo Hamesses Melo; BEZERRA, Mariana Silva. CIDECombustíveis: Tributação indutora e desenvolvimento econômico e ambiental. Revista Direito e Desenvolvimento. João Pessoa, v. 2, n. 4, p. 311-323, 2011. 
DERANI, Cristiane. Direito Ambiental Econômico. 3. ed. São Paulo: Max Limonad, 2008.

DOMINGUES, José Marcos; MOREIRA, Clara Gomes. Contribuição de Intervenção no Domínio Econômico - Combustíveis: Afetação Constitucional da Receita. Contingenciamento e Tredestinação. Revista de Direito Internacional Econômico e Tributário. Brasília, v. 4, n. 2, p. 219-236, 2009.

ENGLISCH, Joachim. Verbrauch- und Aufwandsteuern: § 190. In: KUBE, Hanno et al. (Org.). Staat und Verfassung, Leitgedanken des Rechts: Paul Kirchhof zum 70. Geburtstag. Heidelberg: C. F. Müller, 2013. p. 20812091.

FENSTERSEIFER, Tiago. Direitos fundamentais e proteção do ambiente: a dimensão ecológica da dignidade humana no marco jurídico-constitucional do Estado socioambiental de direito. Porto Alegre: Livraria do Advogado, 2008.

FIORILLO, Celso Antonio Pacheco; FERREIRA, Renata Marques. Direito ambiental tributário. 3. ed. São Paulo: Saraiva, 2010.

GASSEN, Valcir; D’ARAÚJO, Pedro Júlio Sales; PAULINO, Sandra. Tributação sobre Consumo: o esforço em onerar mais quem ganha menos. Sequência. Porto Alegre, v. 34, n. 66, p. 213-234, 2013.

GLASER, Andreas. Verfassungs- und unionsrechtliche Grenzen steuerlicher Lenkung. Steuer und Wirtschaft. Köln, n. 2, p. 168-181, 2012.

GOMES, Flávia Helena. Das implicações tributárias do desvio de finalidade na destinação do produto arrecadado com a CIDE-combustíveis. Revista de Direito Público. Londrina, v. 3, n. 3, p. 144-162, 2008.

GOSCH, Dietmar. Juristische Beurteilung von Öko-Steuern. Steuer und Wirtschaft. Köln, n. , p. 201-216, 1990.

GUSMÃO, Omara Oliveira de. Proteção ambiental e tributação: O tributo como coadjuvante na concretização do valor constitucional "meio ambiente". Revista tributária e de finanças públicas. São Paulo, v. 14, n. 66, p. 113-148, 2006.

HAAS, Evelyn. Ist die so genannte Ökosteuer verfassungsgemäß? In: 
GRUPP, Klaus; HUFELD, Ulrich (Org.). Recht, Kultur, Finanzen: Festschrift für Reinhard Mussgnug zum 70. Geburtstag am 26. Oktober 2005. Heidelberg: C. F. Müller, 2005. p. 205-215.

HARADA, Kiyoshi. Reforma tributária. Revista tributária e de finanças públicas. São Paulo, v. 21 n. 109, p. 27-41, 2013.

HESSELLE, Vera de. Ökologisch motivierte Normen im geltenden Steuerrecht: Bestandsaufnahme und Bewertung. Stuttgart: Boorberg, 2004.

HEUN, Werner. Artikel 105. In: DREIER, Horst (Org.). GrundgesetzKommentar: Artikel 83 - 146. 2. ed. Tübingen: Mohr Siebeck, 2008. p. 911-939.

HEY, Johanna. § 3 Steuersystem und Steuerverfassungsrecht. In: TIPKE, Klaus; LANG, Joachim (Org.). Steuerrecht. 22. ed. Köln: O. Schmidt, 2015. p. 63-137.

JACHMANN, Monika. Die Rechtfertigung der ökologisch motivierten Steuer. In: OSTERLOH, Lerke; SCHMIDT, Karsten; WEBER, Hermann (Org.). Staat, Wirtschaft, Finanzverfassung: Festschrift für Peter Selmer zum 70. Geburtsag. Berlin: Duncker \& Humbolt, 2004. p. 707-724.

JOBS, A. Throsten. Zur Gesetzgebungskompetenz für Umweltsteuern: Konsequenzen aus den Urteilen des BVerfG vom 7.5.1998 für eine "Ökologische Steuerreform" im Bund. Die öffentliche Verwaltung. Stuttgart, v. 58. p. 1039-1048, 1998.

KHAZZOUM, Bassam; KUDLA, Carsten; REUTER, Ralf. Energie und Steuern: Energie- und Stromsteuerrecht in der Praxis. Wiesbaden: Gabler, 2011.

KIRCHHOF, Paul. Umweltschutz im Abgaben- und Steuerrecht. Köln: O. Schmidt, 1993.

KISKER, Gunter. Staatshaushalt. In: ISENSEE, Josef; KIRCHHOF, Paul (Org.). Handbuch des Staatsrechts der Bundesrepublik Deutschland. Vol. IV. Heidelberg: C. F. Müller, 1990. p. 235-293.

KLOEPFER, Michael. Umweltrecht. 3. ed. München: C. H. Beck, 2004. KUBE, Hanno. Art. 110. In: MAUNZ, Theodor; DÜRIG, Günter; 
HERZOG, Roman (Org.). Kommentar zum Grundgesetz. München: C. H. Beck, 2014.

LIST, Heinrich. Die Ökobesteuerung und das Grundgesetz. BetriebsBerater. Frankfurt am Main, n. 24, p. 1216-1220, 2000.

MATIAS, João Luis Nogueira; MATTEI, Julia. Aspectos comparativos da proteção ambiental no Brasil e na Alemanha. Nomos. Fortaleza, v. 34, n. 2, p. 227-244, 2014. Disponível em: <http://periodicos.ufc.br/index.php/ nomos/article/view/1230>.

MATTEI, Julia. Eine verfassungsrechtlich vergleichende Studie über die Effektuierung des Umweltschutzes durch ökologisch orientierte Steuern in Deutschland und Brasilien. 2016. Tese (Doutorado em Direito), Universität zu Köln, Köln. Disponível em: <http://kups.ub.uni-koeln.de/ $\mathrm{id} /$ eprint/7063>.

MÖSLEIN, Florian. Steuerrecht und Marktstabilität. Juristen Zeitung. Tübingen, v. 67, n. 5, p. 243-251, 2012.

ORGANISATION FOR ECONOMIC CO-OPERATION AND DEVELOPMENT (OECD). Environmental Taxes. Disponível em: $<$ http:// stats.oecd.org/glossary/detail.asp?ID=6437>. Acesso em: 16 fev. 2018.

PEREIRA, Ricardo de Castro; FERREIRA, Pedro Cavalcanti. Avaliação dos impactos macroeconômicos e de bem-estar da reforma tributária no Brasil. Revista Brasileira de Economia de Empresas. Brasília, v. 64, n. 2, p. 191-208, 2010.

REIS, Amanda Madeira; FERREIRA, Celso Antonio Pires. A Contribuição de Intervenção no Domínio Econômico - CIDE como efetivo instrumento de proteção ao meio ambiente. Revista de Direito Tributário e Financeiro, v. 2, n. 2, p. 160-177, 2017. Disponível em: <http://www.indexlaw.org/ index.php/direitotributario/article/view/1365>. Acesso em: 5 mar. 2018.

SANTI, Eurico Marcos Diniz de et al. Tributação, responsabilidade fiscal e desenvolvimento: Direito à transparência: Estudo sobre a destinação da CPMF e da CIDE - Combustíveis. Cadernos direito GV. São Paulo, n. 51, p. 5-68, 2008.

SCHOUERI, Luís Eduardo. Normas tributárias indutoras em matéria 
ambiental. In: TÔRRES, Heleno Taveira (Org.). Direito tributário ambiental. São Paulo: Malheiros, 2005. p. 235-256.

SELMER, Peter. Ökologische Steuerreform, Verfassungsrecht und Bundesverfassungsgericht: Bemerkungen anläßlich der ÖkosteuerEntscheidungen des BVerfG vom 20. April 2004. In: TIPKE, Klaus; SÖHN, Harmut; TRZASKALIK, Christoph (Org.). Gedächtnisschrift für Christoph Trzaskalik. Köln: O. Schmidt, 2005. p. 411-430.

SIEKMANN, Helmut. Vorbemerkungen zu Abschnitt X. In: SACHS, Michael (Org.). Grundgesetz: Kommentar. 7. ed. München: C. H. Beck, 2014. p. 2120-2177.

SILVA, Vanessa Cristina de Lima e; ELALI, André de Souza Dantas. A extrafiscalidade em matéria ambiental: tributação indutora como mecanismo de defesa do meio ambiente. Revista Pesquisas Jurídicas, v. 1, n. 1, p. 47-66, 2012.

SOUZAFILHO, Vano Sérvio Reis de. Tributação ambiental: a possibilidade da cobrança de tributos visando à defesa do meio ambiente. Revista tributária e de finanças públicas. São Paulo, v. 20, n. 103, p. 321-346, 2012.

SOYK, Stefan. Energie- und Stromsteuerrecht: Die besonderen Verbrauchsteuern auf die Energieverwendung. 3. ed. Köln: Heymanns, 2013.

STURM, Bodo; VOGT, Carsten. Umweltökonomik: Eine anwendungsorientierte Einführung. Berlin; Heidelberg: Physica-Verlag, 2011.

TIPKE, Klaus. Die Steuerrechtsordnung I: Wissenschaftsorganisatorische, systematische und grundrechtlich-rechtsstaatliche Grundlagen. 2. ed. Köln: O. Schmidt, 2000.

TÔRRES, Heleno Taveira. Da relação entre competências constitucionais tributária e ambiental: os limites dos chamados "tributos ambientais". In: TÔRRES, Heleno Taveira (Org.). Direito tributário ambiental. São Paulo: Malheiros, 2005. p. 96-156.

TÔRRES, Heleno Taveira. Descompasso entre as políticas ambiental e 
tributária. Consultor Jurídico, 2012. Disponível em: <http://www.conjur. com.br/2012-jun-20/consultor-tributario-descompasso-entre-politicasambiental-tributaria>. Acesso em: 28 ago. 2017.

WALDHOFF, Christian. Die Zwecksteuer: Verfassungsrechtliche Grenzen der rechtlichen Bindung des Aufkommens von Abgaben. Steuer und Wirtschaft. Köln, n. 4, p. 285-313, 2002.

WALDHOFF, Christian. Grundzüge des Finanzrechts des Grundgesetzes. In: ISENSEE, Josef; KIRCHHOF, Paul (Org.). Handbuch des Staatsrechts der Bundesrepublik Deutschland. Vol. V. 3. ed. Heidelberg: C. F. Müller, 2007. p. 813-933.

WEBER-GRELLET, Heinrich. Lenkungssteuern im Rechtssystem. Neue Juristische Wochenschrift. München, n. 50, p. 3657-3664, 2001.

Artigo recebido em: 11/08/2018.

Artigo aceito em: 06/02/2019.

\section{Como citar este artigo (ABNT):}

MATTEI, J.; MATIAS, J. L. N.. A reforma tributária ecológica alemã como paradigma para o Brasil. Veredas do Direito, Belo Horizonte, v. 16, n. 34, p. 205-233, jan./abr. 2019. Disponível em: <http://www.domhelder.edu.br/ revista/index.php/veredas/article/view/1283>. Acesso em: dia mês. ano. 